\title{
TRAUMA EM SOLAR STORMS: O MUNDO SOMBRIO E PERIGOSO DE HANNAH WING
}

JOÃO FELIPE BRUM ${ }^{1}$

UFRGS

MARTA RAMOS OLIVEIRA ${ }^{2}$

UFRGS

\begin{abstract}
RESUMO: Em Solar Storms (publicado em 1995), a autora Linda Hogan explora o universo de pessoas de origem indígena que passaram por experiências profundamente traumáticas. Este artigo analisa a construção de uma das personagens da obra, Hannah Wing, mãe de Angela, a protagonista da narrativa. Para tanto, são levadas em consideração a linguagem e as histórias - dois aspectos muito importantes para os povos nativo-americanos - utilizadas por Hogan para desenvolver a personagem de Hannah, que apresenta traumas de origem transgeracional.
\end{abstract}

PALAVRAS-CHAVE: Solar Storms; literatura indígena norte-americana; trauma; linguagem; histórias.

ABSTRACT: In Solar Storms (1995), writer Linda Hogan explores the universe of indigenous people who experienced profound traumatic experiences. This article focuses on the character of Hannah Wing, the mother of the book's protagonist, Angela. This analysis takes into account how Hogan uses language and stories - two very important aspects for Native Americans -in order to develop Hannah's character, which is deeply damaged by intergenerational trauma.

KEYWORDS: Solar Storms; Native American literature; trauma; language; stories.

\section{Introdução}

\footnotetext{
${ }^{1}$ Estudante de Bacharelado em Letras pela Universidade Federal do Rio Grande do Sul (UFRGS). Orientado pela Profa. Dra. Marta Oliveira. E-mail: joaofbrum@gmail.com .

${ }^{2}$ Professora do Instituto de Letras da UFRGS, onde leciona disciplinas de literatura e cultura norteamericanas e orienta estágios de tradução na área de literatura indígena. Sua dissertação, entitulada "The Politics of Memory in Harold Pinter's Ashes to Ashes", e sua tese, "Weaving Life Stories: Healing Selves in Native American Autobiographical Narratives", estão disponíveis através do Portal SABi. E-mail: marta.ramos.oliveira@gmail.com .
}

Espaço Ameríndio, Porto Alegre, v. 8, n. 2, p. 65-86, jul./dez. 2014. 
Escrito pela autora norte-americana de origem chickasaw Linda Hogan e publicado em 1995, Solar Storms (sem tradução publicada em português) é uma história sobre trauma e recuperação. Angela Jensen (apelidada de Angel), narradora e protagonista da obra, retorna a Adam's Rib, a terra de sua família indígena, e embarca em uma jornada pelos rios que ficam na fronteira entre Estados Unidos e Canadá para descobrir as causas de seus traumas e maneiras de se curar. Essa não é, entretanto, a mesma trajetória percorrida por outras personagens do livro. Para Loretta e Hannah, respectivamente avó e mãe de Angel, a vida não passava de dor e sofrimento, sem possibilidade de fuga.

Como a personagem de Loretta não é muito explorada ao longo da narrativa, o foco deste trabalho será Hannah, cujas descrições despertam, ao mesmo tempo, choque e fascinação. Hogan aborda o universo sombrio e perigoso de uma pessoa profundamente traumatizada a partir de uma perspectiva bastante incomum. As palavras, as imagens e as comparações utilizadas pela autora não são aquelas com que o leitor ocidental está acostumado, daí a importância de mostrar como esse ponto de vista diferente pode ser rico e relevante.

O objetivo deste artigo é verificar como Hogan constrói a personagem de Hannah por meio da linguagem e das histórias tradicionais indígenas. Primeiro, será explicada a importância desses dois aspectos, linguagem e histórias, para os povos nativos. Depois, será discutido como os traumas podem afetar a vida das pessoas. Por fim, com base nessas questões, será analisada Hannah em Solar Storms.

\section{Linguagem e histórias}

A literatura indígena norte-americana e suas características peculiares intrigam leitores e críticos ocidentais há bastante tempo. Como afirma Paula Gunn Allen (1983), esse efeito é resultado de duas maneiras distintas de entender o mundo:

A literatura indígena norte-americana tradicional não é parecida com a literatura ocidental, porque os pressupostos básicos sobre o universo e, portanto, a realidade básica vivida por povos tribais e por povos 
ocidentais são diferentes ${ }^{3}$ (ALLEN, 1983, p. 3-4).

Segundo Allen (1983), os nativos norte-americanos acreditam que animais, árvores, flores, pedras, rios, tudo deva ser tratado com respeito, e os humanos não deveriam se considerar mais importantes ou mais privilegiados que os outros seres; são apenas diferentes. Eles sempre buscam o equilíbrio em suas vidas, não somente para o indivíduo, mas principalmente para a comunidade, e isso só pode ser atingido por meio de uma boa conexão com o meio ambiente. Esses aspectos se refletem na relação deles com a linguagem e em como eles a utilizam para descrever suas percepções da realidade.

Portanto, quando um autor de origem indígena cria uma narrativa ficcional, ele insere nela conhecimentos indígenas baseados em uma perspectiva indígena - o que é a mesma coisa que um escritor ocidental faz, mas baseado em outra concepção de mundo. Em Solar Storms, a palavra "trauma" nunca é mencionada, mas os leitores podem compreender que esse é o tema principal da obra. Como isso é possível? As descrições das personagens Loretta, Hannah, Angel e até Henriet (irmã mais nova de Angel) deixam isso bem claro. Na verdade, o mais surpreendente não é o tema propriamente dito, mas a maneira como a autora utiliza a linguagem para construir a história - as personagens traumatizadas estão sempre cercadas por mistérios, presenças sombrias e forças malignas, e suas feridas são tão profundas que algumas não podem mais ser salvas.

Além disso, é fundamental apontar que os nativos americanos acreditam no poder das palavras e da narração de histórias. De acordo com Leslie Marmon Silko (1981, p. 55), uma escritora do Pueblo Laguna, "não pensamos nas palavras como sendo isoladas umas das outras: as palavras estão sempre acompanhadas de outras palavras, e as outras palavras quase sempre fazem parte de algum tipo de história"4. Irene S. Vernon (2012, p. 46) acrescenta que

a narração de histórias é um dos aspectos principais da

\footnotetext{
${ }^{3}$ As citações diretas deste artigo foram escritas originalmente em inglês e traduzidas por este autor. Os textos de partida sempre serão incluídos em notas de rodapé. "[T]raditional American Indian literature is not similar to Western literature, because the basic assumptions about the universe and, therefore, the basic reality experienced by tribal peoples and by Western peoples are not the same".

4 “[W] don't think of words as being alone: words are always with other words, and the other words are almost always in a story of some sort".
}

Espaço Ameríndio, Porto Alegre, v. 8, n. 2, p. 65-86, jul./dez. 2014. 
cultura nativa, uma vez que as histórias tradicionais se baseiam em honrar todo tipo de vida (pessoas, animais, plantas) e são usadas para transmitir os costumes e a história. É através das histórias que o povo nativo aprende quem ele é, de onde ele vem e como deve agir ${ }^{5}$ (VERNON, 2012, p. 46).

A cultura indígena está muito presente nas histórias contadas de geração em geração, e esse ato de transmissão é considerado essencial para a preservação das tradições.

Angel aprende muitas histórias após conhecer Dora-Rouge (trisavó de Angel), Agnes (filha de Dora-Rouge e bisavó de Angel), Bush (ex-mulher do avô de Angel e ex-nora de Agnes) e outras pessoas da comunidade, mas uma dessas narrações contribui de forma significativa para entender a personagem de Hannah através do olhar indígena. Há três referências a essa história ao longo da obra, que serão exploradas no capítulo 3. Bastante popular entre as tribos nativas da região dos Grandes Lagos, o relato aborda a figura do wétiko. Jack Forbes afirma que

Wétiko é um termo surgido na tribo Cree (windigo na língua Ojibway, wintiko na língua Powhatan) que se refere a um canibal ou, mais especificamente, a uma pessoa ou um espírito maligno que aterroriza outras criaturas por meio de maldades terríveis, incluindo 0 canibalismo ${ }^{6}$ (FORBES, 2008, p. 24).

Sem encontrar outras explicações para o comportamento de Hannah, as pessoas associam-na à história desse espírito maligno, dizendo que ele habitava o seu corpo e era o responsável por destruir sua vida.

\section{Trauma}

\footnotetext{
5 "Storytelling is a major aspect of Native culture, for traditional stories are based on honoring all life (people, animals, plants) and are used to pass down customs and history. It is through stories that Native people learn who they are, where they come from, and how to act"

6 "Wétiko is a Cree term (windigo in Ojibway, wintiko in Powhatan) which refers to a cannibal or, more specifically, to an evil person or spirit who terrorizes other creatures by means of terrible evil acts, including cannibalism".
}

Espaço Ameríndio, Porto Alegre, v. 8, n. 2, p. 65-86, jul./dez. 2014. 
Em Solar Storms, traumas afetam não apenas os indivíduos isoladamente, mas também comunidades indígenas inteiras que foram massacradas pelos homens brancos. Adam's Rib e Two-Town, os principais cenários onde se passa a narrativa, estão na rota desse massacre. Na primeira cidade, caçadores brancos abandonaram suas mulheres indígenas e filhos mestiços depois de terem matado todos os animais; na segunda, os jovens nativos sucumbiram às drogas e ao álcool. As duas estavam sendo devastadas pela construção de represas. "Por meio da protagonista, Angela Jensen (conhecida como Angel), Hogan transmite uma experiência individual chocante ao mesmo tempo em que também expressa o trauma coletivo e o sofrimento do povo nativo"7, afirma Vernon (2012, p. 34). Para ela, Hogan revela assim o fenômeno do trauma transgeracional, "a ideia de que, se o trauma numa população não é tratado, as consequências são passadas para as gerações subsequentes, tornando-se cada vez mais graves"8 (VERNON, 2012 , p. 35). Esse problema está muito presente nas comunidades indígenas do romance e na família Wing.

De acordo com Vernon,

[a]s descrições vívidas de Hannah feitas por Hogan expressam características básicas do transtorno do estresse pós-traumático. [...] Hannah torturava outras pessoas, roubava, mentia e não conseguia dormir. Da mesma forma que sua mãe, ela não tinha amor, consciência, crença, nada dentro dela ${ }^{9}$ (VERNON, 2012, p. 38).

Judith Herman (1997) divide os sintomas do transtorno do estresse pós-traumático em três categorias principais: hiperexcitabilidade (insônia, sobressaltos, hipervigilância, alto nível de irritabilidade), intrusão (flashbacks, pesadelos, fixação no trauma) e constrição (alteração da consciência, torpor). Hannah é afetada pela maioria desses sintomas.

\footnotetext{
7 "Through the protagonist, Angela Jensen (aka Angel), Hogan conveys a shocking individual experience while also expressing the collective trauma and suffering of Native people".

8 "[T] $]$ he idea that if trauma among a population is not addressed, the consequences can continue into subsequent generations, becoming more severe with each passing".

9 "Hogan's vivid descriptions of Hannah express essential features of post-traumatic stress disorder. [...] Hannah tortured others, she stole, she lied, and she could not sleep. Like her mother, she had no love, no conscience, no belief, nothing left in her".
}

Espaço Ameríndio, Porto Alegre, v. 8, n. 2, p. 65-86, jul./dez. 2014. 
Os eventos traumáticos na vida de Hannah aconteceram quando ela ainda era criança. Herman (1997, p. 96) afirma que "o trauma recorrente durante a infância forma e deforma a personalidade"10. Além disso, "o abuso infantil crônico acontece em um ambiente familiar de terror generalizado, no qual relações básicas de cuidado foram profundamente rompidas"11 (HERMAN, 1997, p. 98). Foi exatamente por isso que Hannah passou quando vivia com Loretta, que também foi vítima de abusos durante a infância. Herman explica que colocar em palavras o que causou o trauma é o primeiro passo para começar a recuperação; Hannah, no entanto, não tem oportunidade para fazer isso. Para Vernon (2012, p. 42), "Hannah sofreu danos irreparáveis; ela é uma mulher com um coração congelado, uma mulher que caiu nas garras do gelo, uma mulher que 'vivia em uma casa de neve'"12.

\section{Hannah}

A primeira descrição de Hannah surge no prólogo do livro, quando Agnes conta um de seus sonhos a Angel - e sonhos são muito significativos para os nativos. Ela pescava em Lake Grand quando, de repente, a água congelou e Hannah apareceu sob o gelo: "Eu tinha medo dela. Todos tínhamos. O que havia de errado com ela nós não sabíamos nomear, e desconfiávamos de coisas sem nome"13 (HOGAN, 1997, p. 12). Agnes acredita que sua neta não é humana, mas falta-lhe uma explicação. Ela recorre a algumas histórias antigas do povo Cree sobre "o coração congelado do mal que era faminto, invejoso e ganancioso, como havia enganado pessoas para que morressem ou ficassem doentes ou levado-as à loucura"14 (HOGAN, 1997, p. 12-13), e a única salvação era aquecer o coração da pessoa. Infelizmente, não era possível fazer isso com Hannah: "[ela] se viu num caminho sem fim para um

\footnotetext{
10 " [R]epeated trauma in childhood forms and deforms the personality".

11 "Chronic childhood abuse takes place in a familial climate of pervasive terror, in which ordinary caretaking relationships have been profoundly disrupted".

12 "Hannah is damaged beyond repair; she is a woman who has a frozen heart, a woman who was in the grip of ice, a woman who "lived in a house of snow"'.

13 "I was afraid of her. We all were. What was wrong with her we couldn't name and we distrusted such things as had no name".

14 "[T] $]$ he frozen heart of evil that was hunger, envy, and greed, how it had tricked people into death or illness or made them go insane".
}

Espaço Ameríndio, Porto Alegre, v. 8, n. 2, p. 65-86, jul./dez. 2014. 
submundo. Ela estava ferida. Era perigosa. E não havia como aquecer seu coração"15 (HOGAN, 1997, p. 13).

Hannah é introduzida ao leitor através dessa descrição forte e misteriosa. Agnes utiliza certas palavras que são constantemente relacionadas a Hannah ao longo da narrativa: gelo, congelado, temor, mal, medo, perigo, ferida, frio, violência, choro, luta. Não há alegria nem felicidade quando ela é lembrada, apenas dor e sofrimento. Nesse ponto, ainda não se sabe as causas de tantos estragos, mas fica evidente que ela é uma mulher muito problemática e que afetou a vida de outros personagens.

Há mais uma informação relevante nesse trecho: a história antiga dos Cree. Se comparados aos ocidentais, os índios entendem o mundo de forma completamente distinta, e as histórias têm um papel muito importante para eles. Eles mantêm vivos seus conhecimentos e sua memória ao contar histórias às gerações seguintes. A história do "coração congelado do mal", ou o wétiko, é bastante difundida entre as tribos indígenas norte-americanas. Na primeira menção, Hannah já é associada a essa criatura terrível, capaz de coisas horrendas. Como diz Agnes, ela vivia em um mundo tão gelado que ninguém poderia aquecer seu coração.

Quando Angel chega a Adam's Rib e conhece Agnes, Dora-Rouge e, mais tarde, Bush, ela se familiariza, pouco a pouco, com a sua própria história, incluindo quem é a sua mãe. Narradora da maior parte do livro, Angel fala sobre a mãe de forma fragmentada. No capítulo 1, ela conta este episódio: certa vez, Bush levou Hannah a um dos velhos que moravam na Hundred-Year-Old Road (rua onde viviam os idosos da cidade) com a esperança de que ele fosse dar um diagnóstico para o problema da menina. Ele se desculpou, no entanto, e disse que isso estava além dos seus poderes: "Não estava ao alcance do poder de nenhuma outra pessoa, porque a minha mãe havia sido subjugada por uma força violenta e terrível. Habitava sua carne, seus ossos e seu espírito"16 (HOGAN, 1997, p. 21-22). A ideia se repete: existe algo perverso habitando o corpo de Hannah, algo que ninguém é capaz de

15 "[She] stood at the bottomless passage to an underworld. She was wounded. She was dangerous. And there was no thawing for her heart".

16 "Nor was it in the power of anyone else, for my mother had been taken over by some terrible and violent force. It inhabited her flesh, bone, and spirit".

Espaço Ameríndio, Porto Alegre, v. 8, n. 2, p. 65-86, jul./dez. 2014. 
explicar, nem mesmo os sábios da comunidade. É interessante notar, entretanto, que as pessoas não responsabilizam Hannah por todo esse mal - a força maligna dentro dela é a culpada.

Angel se apresenta como uma adolescente com cabelo ruivo e cicatrizes no lado direito do rosto.

As cicatrizes haviam moldado a minha vida. Eu estava marcada e sabia que as marcas tinham a ver com a minha mãe [...]. Embora não soubesse como eu obtive as cicatrizes, sabia que elas eram o motivo pelo qual eu havia sido levada da minha mãe vários anos antes ${ }^{17}$ (HOGAN, 1997, p. 25).

Surgem então novas informações a respeito de Hannah: ela costumava bater na filha com tanta força que o rosto da menina ficou cheio de cicatrizes, e foi assim que perdeu a guarda da criança. Angel não recorda desses ataques, mas os resultados deixaram marcas de medo constante ("medo de tudo - silêncio, proximidade, imobilidade e como me fazia pensar e sentir"18, p. 26) e raiva ("meus ataques silenciosos de fúria"19, p. 27). Mudar-se para Adam's Rib e encontrar a família são as únicas maneiras de conseguir lidar com seus traumas.

Hannah era

a garota que foi carregada pelas águas tempestuosas em 1949, encharcada por uma tempestade tão violenta que arremessara peixes na terra. Naquela época, ela tinha dez anos e estava gelada, a única coisa arremessada que ainda apresentava algum resquício de vida em seu interior"20 (HOGAN, 1997, p. 34).

Portanto, ela não nasceu em Adam's Rib, e sua chegada no local foi misteriosa. Ela foi trazida por águas turbulentas, vinda de lugar nenhum, sozinha, quase congelando - o único ser a sobreviver à tempestade. A expressão "gelada" é utilizada para descrevê-la e reforça a ideia de uma pessoa entorpecida.

\footnotetext{
17 "Scars had shaped my life. I was marked and I knew the marks had something to do with my mother [...]. While I never knew how I got the scars, I knew they were the reason I'd been taken from my mother so many years before".

18 "[F] ear of everything-silence, closeness, motionlessness and how it made me think and feel".

19 "[M]y quiet rages".

20 " [G] irl who washed up from stormy waters in 1949, washed in from a storm so fierce it blew fish onto the land. At that time she was ten years old and icy cold, the only thing blown in that had a spark of life remaining inside of it".
}

Espaço Ameríndio, Porto Alegre, v. 8, n. 2, p. 65-86, jul./dez. 2014. 
Loretta Wing, mãe de Hannah, é apresentada por Agnes. Ela veio de Elk Island e cheirava a cianeto, porque seu povo "ficou tão faminto que comeu carcaças envenenadas de cervos que os colonizadores haviam deixado para os lobos"21 (HOGAN, 1997, p. 38). A maioria morreu, mas Loretta conseguiu sobreviver. Um dia, ela apareceu em Adam's Rib, e sua excentricidade atraiu muitos homens, embora costumassem dizer que havia algo terrível dentro dela. Alguns acreditavam que se tratava de um mau espírito, mas Agnes discordava:

A maldição na vida daquela pobre menina surgiu quando teve de assistir a morte das pessoas desesperadas de sua tribo. [...] Como ela sobreviveu, eu não sabia. Mas depois disso, quando ainda era uma garota, ela fora levada e usada por homens que a alimentavam, mas também batiam nela e a forçavam. Foi assim que um dia ela se tornou a pessoa que fere os outros. Foi algo transmitido. Eu quase podia ouvir as vozes deles quando ela falava, balbuciando por trás da voz dela, vozes de homens falando inglês. Algo assustador vivia por trás da voz dela. [...] Loretta não era o pecado original. Algo dentro dela havia se levantado, ido embora e deixado o resto para trás. Não sobrara nenhum amor dentro dela. Nenhuma fé. Nem um pingo de consciência. Não sobrara nada dentro dela22 (HOGAN, 1997, p. 39).

A história de Loretta é a chave para entender as personagens de Hannah e Angel. Ela passou por um evento extremamente traumático (a morte de seu povo) e acabou abandonada quando era muito jovem. Depois disso, a fome fez com que tomasse as atitudes mais desesperadas, como ter relacionamentos sexuais com homens quaisquer em troca de comida. Eles batiam nela frequentemente. Ela cresceu tomada por sofrimento e dor, e esses sentimentos tornaram-na incapaz de amar outras pessoas. Por fim, ela assumiu o papel de quem abusa dos outros. Como explica Vernon (2012, p. 37), "Hogan constrói

\footnotetext{
21 "[B]ecame so hungry they ate poisoned carcasses of deer that the settlers left out for the wolves".

${ }^{22}$ The curse on that poor girl's life came from watching the desperate people of her tribe die. [...] How she'd lived, I didn't know. But after that, when she was still a girl, she'd been taken and used by men who fed her and beat her and forced her. That was how one day she became the one who hurt others. It was passed down. I could almost hear their voices when she talked, babbling behind hers, men's voices speaking English. Something scary lived behind her voice. [...] Loretta wasn't the original sin. It was just that something inside her had up and walked away and left the rest behind. There was no love left in her. There was no belief. Not a bit of conscience. There wasn't anything left in her.
}

Espaço Ameríndio, Porto Alegre, v. 8, n. 2, p. 65-86, jul./dez. 2014. 
uma história com camadas de trauma vivido e testemunhado, traumas que emanam dos colonizadores não-nativos e são transmitidos de Loretta para Hannah e, depois, para Angel"23.

Harold, filho de Agnes, deixou sua mulher, Bush, para fugir com Loretta. Eles nunca mais foram vistos. Vários anos depois, uma garota com "a cara de Harold e o cabelo ruivo de Loretta" 24 emergiu das águas tempestuosas, como lembra Agnes: "Ela cheirava às mesmas amêndoas amargas. Era um odor mais fraco, mas estava lá do mesmo jeito. Acreditávamos que ela tinha por volta de dez anos. Tinha olhos vazios que nunca esquecerei"25 (HOGAN, 1997, p. 40). Bush assumiu a responsabilidade e decidiu cuidar de Hannah. Desde o primeiro dia, notaram o vazio no olhar da criança, como se ela nunca estivesse presente. De acordo com Vernon,

o leitor precisa imaginar como era o relacionamento de Hannah com sua mãe, uma vez que Hogan não preencheu essa lacuna. O que ela fornece aos leitores, no entanto, é a percepção de transmissão do trauma, uma herança transgeracional por meio da qual as escolhas de vida e os comportamentos de Hannah imitam os de sua mãe ${ }^{26}$ (VERNON, 2012, p. 38).

Na casa de Bush, existia um altar com fotos do passado, que são analisadas por Angel:

Em uma das fotografias, Hannah Wing me segurava em seus braços com desconforto. Ela não nascera para ser mãe, eu podia perceber. Enrolada firmemente em um cobertor, eu olhava para ela com olhos assustados, e parecia que mesmo naquela época eu já tentava me afastar dela 27 (HOGAN, 1997, p. 71).

Hannah era uma jovem traumatizada, sem nenhuma condição de

\footnotetext{
23 "Hogan builds a story with layers of trauma experienced and witnessed, traumas that emanate from non-Native colonizers and then are passed down from Loretta to Hannah and then to Angel".

24 "Harold's face and Loretta's red hair".

25 "She smelled of the same bitter almonds. It was a fainter odor, but it was still there all the same. We guessed her to be about ten years old. She had empty eyes I'll never forget".

26 "The reader is left to imagine Hannah's relationship with her mother, for Hogan has left the space silent. What she gives readers, however, is a sense of the transmission of trauma, an intergenerational passing whereby Hannah's life choices and behaviors mimic her mother's".

27 "In one photograph, I was held uncomfortably in the arms of Hannah Wing. She was not a natural mother, I could see. Wrapped tightly in a blanket, I looked at her with frightened eyes and it seemed that, even then, I pulled away from her".
}

Espaço Ameríndio, Porto Alegre, v. 8, n. 2, p. 65-86, jul./dez. 2014. 
ter um filho, e até mesmo um bebê podia sentir o perigo. Em uma das fotografias, Angel se vê sorrindo, sem cicatrizes, e percebe que já foi amada por sua família. Mas ela também tem consciência de que sua mãe foi a responsável pela dor que sente: "Hannah, que me desfigurou" 28 (HOGAN, 1997, p. 72). Angel vê sua mãe em outra imagem, uma garotinha com uma presença sombria ao seu redor: "Atrás dela, havia algo ou alguém, um espírito, um fantasma, uma outra presença que era apenas uma sombra ou um borrão, mas distintamente real"29 (HOGAN, 1997, p. 72). Definir a existência de Hannah é muito complicado para todos.

No início, os dias em Fur Island são frustrantes. Angel vai para lá esperando conhecer toda a sua história, mas Bush fornece apenas pequenas doses de informação a cada dia. Angel acredita que se trata de uma estratégia para mantê-la no local. Há outro motivo: sua história é tão complexa e traumática que precisa ser contada aos poucos, para o bem da narradora e da ouvinte. Certo dia, Bush compara Hannah ao vento: algumas vezes, ela era o vento gelado e furioso do inverno, pronto para causar destruição. Outras vezes, ela era um vento mais quente, mais calmo: "Éramos enganados nesses momentos. Deixávamos ela se aproximar e daí ela se transformava em gelo e se voltava contra nós'”30 (HOGAN, 1997, p. 76). Passado um tempo, Bush se solta e passa a falar mais de Hannah, "a menina preenchida pelo gelo"31 (HOGAN, 1997, p. 94).

No outono, Bush finalmente decide contar como era sua vida com Hannah, uma vez que Angel precisava conhecer a própria história do começo. Bush utiliza mais uma analogia: "'Sua mãe era uma porta [...]. Sempre fechada. Mas às vezes eu acreditava que ela era uma janela, na verdade, porque através dela eu vislumbrava cenas de sofrimento"'32 (HOGAN, 1997, p. 96). Bush, Agnes e Dora-Rouge recorrem constantemente a comparações para tentar descrever Hannah:

\footnotetext{
28 "Hannah, who had disfigured me".

29 "Behind her, there was something or someone, a spirit, a ghost, another presence who was only a shadow or blur, but distinctly real".

30 "'We were fooled then. We'd let her near and then she changed into ice and turned against us"”.

31 "[T]

32 "Your mother was a door [...]. Always closed. But sometimes I thought she was a window, instead, because through her I glimpsed scenes of suffering"”.
}

Espaço Ameríndio, Porto Alegre, v. 8, n. 2, p. 65-86, jul./dez. 2014. 
[...] as mulheres diziam que a minha mãe era uma escada sem destino. Era uma casa em chamas, alimentando-se do ar dos outros. Ela não tinha nenhuma base, nem escoras, nem vigas. Sempre achavam que ela estava a um passo de entrar em colapso $^{33}$ (HOGAN, 1997, p. 97).

Hannah não tinha a estrutura psicológica e emocional necessária para viver em sociedade, e ninguém podia ajudá-la.

Como narradora, Bush faz a descrição mais profunda e abrangente de Hannah. Ela diz que um dia uma garota saiu de águas furiosas sem nada além de um pente e suas roupas. "Parecia que ela havia nascido da tempestade"34 (HOGAN, 1997, p. 97). Naquele momento, Agnes e Bush a reconheceram como a filha de Harold e Loretta, em função do cabelo e do cheiro. A menina não emitia nenhum som; as duas temiam que ela pudesse parar de respirar. Embora estivesse gelada, Hannah não queria trocar de roupa. Todos percebiam que havia algo de errado, mas ela pertencia à família, então as mulheres decidiram tomar conta dela.

Buscando uma explicação para a sobrevivência de Hannah, Bush notou as unhas quebradas, o que poderia significar que a menina havia se agarrado a um pedaço de madeira durante a tempestade. Agnes sugeriu que um espírito poderia tê-la ajudado, mas Bush não acreditava em superstições. Logo a garota se tornou um problema para a comunidade. Uma vizinha a acusou de ter roubado seu xale. Quando Bush indagou Hannah a respeito, "ela olhou diretamente para mim e disse que não havia roubado. Eu podia quase acreditar nela, embora a houvesse visto enrolada no xale. Mas a expressão honesta dela me fez duvidar dos meus próprios olhos"35 (HOGAN, 1997, p. 97). Trata-se, provavelmente, de um caso de transtorno de personalidade, uma consequência dos traumas pelos quais ela passou. Na sua percepção, ela não era a pessoa que roubava. Ela não parou de roubar, no entanto, e costumava usar todas as peças sobrepostas. "Acho que aquelas roupas

\footnotetext{
33 " [T] $]$ he women said that my mother was stairs with no destination. She was a burning house, feeding on the air of others. She had no more foundation, no struts, no beams. Always, a person would think she was one step away from collapsing".

34 "It looked like she was born of the storm".

35 " "[S]he looked right at me and said she hadn't taken it. I could almost believe her, even though I'd seen her wrapped up in it. But her look of honesty made me doubt my own eyes".
}

Espaço Ameríndio, Porto Alegre, v. 8, n. 2, p. 65-86, jul./dez. 2014. 
eram a única proteção que ela tinha; a única pele entre ela e todo o resto"36 (HOGAN, 1997, p. 98), afirma Bush.

Hannah era, sem dúvida, uma garota atormentada. Segundo Bush, "seus olhos não confiavam em nada nem ninguém. Eram escuros e sem vida. Sem luz. Era a expressão que os torturados tinham"37 (HOGAN, 1997, p. 98). Como Hannah vivia em um silêncio inacessível, Bush não tinha certeza do que havia acontecido com ela, mas todos os sinais indicavam torturas intensas. Ela havia sido ferida diversas vezes por outras pessoas, incluindo, provavelmente, a própria mãe; era a única explicação para os seus atos.

Bush se considerava uma mulher corajosa, que nunca havia sentido medo de nada - até a chegada de Hannah. "Com ela, até os cantos da casa ficavam escuros. Eles pareciam sentir dor. Você podia sentir. Podia quase ver"38 (HOGAN, 1997, p. 98), descreve. Embora as pessoas dissessem que era "um espírito maligno, um coração de gelo"39 (HOGAN, 1997, p. 98), Bush se recusava a pensar o mesmo, porque acreditava no poder do amor e ainda esperava encontrar uma cura para os problemas da menina.

Mais um sintoma do transtorno do estresse pós-traumático é revelado por Bush: Hannah nunca dormia. "Ela caminhava durante a noite. Como se estivesse presa, ou como se algo estivesse preso dentro dela. Não era insônia ou se revirar na cama, sabe. Ela não dormia nada"40 (HOGAN, 1997, p. 98), como se não conseguisse se libertar do sofrimento. Durante o dia, ela sentava em um canto e ficava quase invisível, como se estivesse tentando se esconder de algo perigoso. Entretanto, o perigo habitava seu corpo, e era impossível escapar dele. Vernon (2012, p. 38) explica que "sintomas do TEPT, como o afastamento dos outros, a incapacidade de amar, a dificuldade de dormir, a ansiedade e as lembranças perturbadoras do passado,

\footnotetext{
36 "I think now that clothes were the only protection she had; the only skin between her and all the rest".

37 "Her eyes had no trust, not in anything or anyone. They were dark and flat. No light. It was the expression the tortured wear".

38 "[W]ith her, even the corners of the house were dark. They seemed to be in pain. You could feel it. You could almost see it".

39 "[A] bad spirit, a heart of ice".

40 "She paced at night. Like she was trapped, or something was trapped in her. Not insomnia or tossing and turning in bed, you understand. She didn't sleep at all”.
}

Espaço Ameríndio, Porto Alegre, v. 8, n. 2, p. 65-86, jul./dez. 2014. 
assombravam Hannah"41.

A memória mais significativa de Bush era de um banho. Certo dia, quando ela não aguentava mais o cheiro de cianeto, chamou Hannah e mandou-a tirar as roupas. Pela primeira vez, a garota aceitou a ordem e despiu todas as camadas que usava.

Tentei não olhar para ela, me sentia tão mal por ela. Não queria ser um de seus abusadores. [...] Ela ficou só de maiô, muito largo. Mas quando a vi em sua nudez pequena, desprotegida, parei e a encarei. Por baixo de todas as camadas de roupas, sua pele era um traje de cicatrizes. Havia queimaduras e incisões. Como se alguém tivesse escrito nela. As assinaturas dos torturadores, como eu as chamo agora. Fiquei acabada. Chorei. Ela me olhou como se eu fosse uma tola, minhas lágrimas, um sinal de fraqueza. E mais para dentro, eu sabia, havia violações e invasões de outros tipos. Quais eram, eu podia apenas imaginar ${ }^{42}$ (HOGAN, 1997, p. 99).

Não havia mais dúvidas: Hannah havia sido vítima de abusos de diversos tipos durante a infância. As marcas em sua pele confirmavam que ela havia passado por eventos traumáticos e horríveis. Não havia uma ou duas cicatrizes em seu corpo; havia tantas que parecia que ela usava "traje de cicatrizes". Bush encontrou "queimaduras e incisões" que deveriam ter causado uma dor inimaginável. A vida de Hannah estava imersa em um terror interminável - a única saída era entrar em estado de torpor, o que explica seus olhos vazios e sua incapacidade de amar ou de sentir qualquer coisa.

Para Dora-Rouge, a "doença" se chamava memória, e Bush acreditava que essa era a hipótese mais provável: "[E]ra o que não podia ser esquecido, as sombras dos homens que haviam ferido Loretta, as sombras dos assassinos de crianças. O que vivia dentro dela veste a pele

\footnotetext{
41 "PTSD's symptoms of an estrangement from others, an inability to love, difficulty sleeping, anxiety, and having disturbing recollections of her past haunt Hannah".

42 "I tried not to watch her, I felt so bad for her. I didn't want to be one of her abusers. [...] She came down to a swimsuit, much too large. But when I saw her in her small, bare nakedness, I stopped and stared. Beneath all the layers of clothes, her skin was a garment of scars. There were burns and incisions. Like someone had written on her. The signatures of torturers, I call them now. I was overcome. I cried. She looked at me like I was a fool, my tears a sign of weakness. And farther in, I knew, there were violations and invasions of other kinds. What, I could only guess".
}

Espaço Ameríndio, Porto Alegre, v. 8, n. 2, p. 65-86, jul./dez. 2014. 
de crianças"43 (HOGAN, 1997, p. 100). Ela percebeu que Hannah não conseguia dormir à noite porque as sombras dos homens que a haviam maltratado estavam sempre acordadas. Essa presença a assombrava e nunca a deixava em paz. Quando tocou as cicatrizes, Bush sentiu as mãos dos torturadores e lembrou-se do wétiko: "Eles tinham dedos gelados. Tinham corações de gelo. Exatamente como os velhos disseram" 44 .

Em um dos raros momentos em que decidiu falar, Hannah contou para Bush que "uma mão vivia dentro dela. Eram dedos, punho. À noite, rastejava para fora de sua casa, o corpo dela, e tentava molestá-la, estrangulá-la"45 (HOGAN, 1997, p. 100). Bush não deu atenção a essas palavras até o dia em que entrou em casa e algo a empurrou de volta. Embora não fosse supersticiosa, ela sabia que não poderia ter sido Hannah, pois a menina estava no canto mais distante do ambiente. "O que me atingiu era grande e poderoso, e estava gelado. Senti algo sólido, mas não vi nada. Meu cachorro estava vivo na época e latia para o que eu não podia enxergar"46 (HOGAN, 1997, p. 100).

Bush era a única pessoa que se aproximava da garota; os outros tinham medo. Quando elas decidiram recorrer ao Velho da HundredYear-Old Road, ele chamou Hannah de "a casa, o ponto de encontro" 47 (HOGAN, 1997, p. 101), o que foi interpretado por Bush como o local onde tempo, história, genocídio e oceanos de sangue se encontravam, a origem do sofrimento. O Velho disse que ela era um caso de "almas roubadas ou perdidas" 48 , mas nem ele nem ninguém poderia ajudá-la: "Era preciso fazer uma cerimônia, ele disse, cujas palavras fossem tão bonitas que chamassem pássaros dos céus, mas a canção em si romperia a vida do intérprete. Ninguém vivo era forte o bastante para cantá-la"49 (HOGAN, 1997, p. 101). Além disso, "existia uma palavra

\footnotetext{
43 " [I] t was what could not be forgotten, the shadows of men who'd hurt Loretta, the shadows of the killers of children. What lived in her wears the skin of children".

44 "They had ice-cold fingers. They had hearts of ice. Just like the old people said".

45 "[A] hand lived inside her. It was fingers, fist. At night it crept out of its home, her body, and tried to molest her, to strangle her".

46 "What struck me was powerful and large, and it was cold. It felt solid but I saw nothing. My dog was alive then, barking at what I couldn't see".

47 "[Th]e house, the meeting place".

48 "[L] ost or stolen souls".

49 "What was needed was a ceremony, he said, the words of which were so beautiful that they called birds out of the sky, but the song itself would break the singer's life. No one still alive was strong enough to sing it".
}

Espaço Ameríndio, Porto Alegre, v. 8, n. 2, p. 65-86, jul./dez. 2014. 
para o que havia de errado com ela, ele afirmou, mas ninguém a pronunciaria. Eles tinham medo que a coisa escutasse o próprio nome e viesse atrás eles"50 (HOGAN, 1997, p. 101). Nesse ponto, surge a voz da tradição indígena: conforme as histórias, somente uma cerimônia poderia curar Hannah.

Certa vez, Hannah contou a Bush sobre um homem que a havia machucado. Elas haviam passado todo o inverno sozinhas, então só poderia ser uma mentira, mas as evidências mostravam o contrário: as calças da menina haviam sido alargadas. Em outra ocasião, ela disse que um fantasma havia desabotoado seu vestido: "Era verdade. O vestido dela estava aberto, e ela, Hannah, tinha uma expressão de terror no rosto"51 (HOGAN, 1997, p. 103). Ela também quebrou uma janela na frente de Bush e negou ter feito isso. "Levou um tempo até eu perceber que ela falara a verdade. Que um homem vinha durante a noite, um fantasma. De qualquer forma, era verdade para ela. Por causa dos outros dentro dela. Eles haviam feito o que ela negava. Eles eram [...] perigosos"52, refletiu Bush. Como afirmou o Velho, apenas uma cerimônia poderia trazer de volta a alma da garota, então Bush decidiu tentar. Ela se preparou e, um dia, adentrou o mundo de Hannah para confrontar as forças malignas:

Eu vi a mão da qual ela falava, escutei as vozes em línguas que nenhum de nós conhecia. Podia ver como era perigoso. Um lugar inescapável sem nenhum mapa. Dentro dele estavam as ruínas dos humanos. Crianças queimadas estavam lá, assim como o fogo ${ }^{53}$ (HOGAN, 1997, p. 103).

Bush teve de reunir todas as suas forças para retornar ao seu próprio mundo. Nesse momento, ela soube que não havia salvação para a menina traumatizada.

Outro episódio foi o assassinato do cão de Bush: "Ela o chutou.

\footnotetext{
50 " [T] $]$ here was a word for what was wrong with her, he said, but no one would say it. They were afraid it would hear its name and come to them".

51 "It was true. Her dress was open, and she, Hannah, had a look of terror on her face".

52 "It took a while before I knew she told the truth. That there was a man come in the night, a ghost. Anyway, it was the truth to her. Because of the others inside her. They were the ones who had done what she denied. They were [...] dangerous".

53 "I saw the hand she spoke of, heard the voices in languages neither of us knew. I could see how dangerous it was. An inescapable place with no map for it. Inside were the ruins of humans. Burned children were in there, as well as fire".
}

Espaço Ameríndio, Porto Alegre, v. 8, n. 2, p. 65-86, jul./dez. 2014. 
Havia agulhas na boca, no nariz e nas orelhas dele, e ele havia sofrido cortes, o sangue vermelho no pelo, emaranhado, uma pata cortada fora. Morreu arfando, a língua solta para fora da boca"54 (HOGAN, 1997, p. 104). Hannah feria os outros da mesma forma como havia sido ferida e não sentia remorso. Na verdade, ela não sentia nada; era oca, como uma árvore morta. Quando ela foi embora, primeiro para o norte e depois para Oklahoma, eles "ficaram aliviados que ela se fora"55 (HOGAN, 1997, p. 104). Quando retornou, estava grávida de Angel: "Precisávamos mantê-la aqui. Sabíamos que ela mataria você"56 (HOGAN, 1997, p. 105). Não há nenhuma referência ao pai ao longo da narrativa. Hannah agia da mesma maneira que sua mãe, Loretta - ela tinha relações sexuais com homens em troca de comida, então era quase impossível identificar o pai. Angel também não se mostra interessada em conhecêlo.

O nascimento de Angel se deu durante um inverno rigoroso, quando havia tanta neve que os tetos das casas chegavam a desmoronar com o peso. De acordo com Bush, "a parteira disse que ouviu você chorando quando ainda estava dentro da sua mãe"57 (HOGAN, 1997, p. 109). Hannah vivia em uma casa de um cômodo com um caçador, "um homem que abrigava jovens problemáticas sob o pretexto de ajudálas"58, mas ele havia viajado para o norte para conferir suas armadilhas. Embora o teto estivesse começando a ceder, a parteira "receava sair para limpar a neve. Ela não queria deixar você sozinha com Hannah. Ela temia que você estivesse em perigo. Ela pressentiu o que viria a seguir"59 (HOGAN, 1997, p. 109). A parteira permaneceu lá, alimentando e cuidando do bebê: "Os seios de Hannah estavam secos. Como sua mente e seu coração, seu corpo não tinha nada a oferecer. Já havia abandonado você"60 (HOGAN, 1997, p. 110). Hannah rejeitou o bebê desde o segundo em que deu à luz, e essa repulsão tornou seu corpo

\footnotetext{
54 "She kicked him. There were needles in his mouth and nose and ears, and he'd been cut, the red blood on the fur, matted, one foot cut off. He died panting, his tongue hanging out of his mouth".

55 "[They] were grateful she was gone".

56 "Then we needed to keep her here. We knew she would kill you".

57 "[T] $]$ he midwife said she heard you crying when you were still inside your mother".

58 "[A] man who took in troubled young girls on the pretext of helping them".

59 "[She] was afraid to go out and clean it off. She did not want to leave you alone with Hannah. She feared you were in danger. She felt what was to come".

60 "Hannah's breasts were dry. Like her mind and her heart, her body had nothing to offer. It had already abandoned you".
}

Espaço Ameríndio, Porto Alegre, v. 8, n. 2, p. 65-86, jul./dez. 2014. 
incapaz de produzir leite.

Quando a parteira achou que Hannah havia dormido, saiu para limpar a neve de cima do telhado. Quando retornou, Hannah trancou a porta e não deixou a mulher entrar. Com medo do que Hannah poderia fazer, a parteira enfrentou a neve e o vento cortante para chegar a Bush, que era a única pessoa que Hannah escutaria. "Nós nos apressamos, quase correndo, as duas certas de que você estaria machucada"61 (HOGAN, 1997, p. 111), disse Bush. Quando elas entraram na casa, o bebê não estava à vista: "Hannah estava sentada numa cadeira de balanço do outro lado do quarto, as costas viradas para a porta. 'Não é o meu bebê', ela disse. 'Meu bebê morreu no parto'"62. Ela havia tentando se livrar do bebê, deixando-o do lado de fora, entre os galhos de uma bétula, para morrer congelado. "Afastem o bebê de mim. Ele não é meu'"63, Hannah avisou. Mas Angel conseguiu sobreviver, assim como sua mãe havia sobrevivido às águas tempestuosas.

Quando ainda procurava por sua família, antes de chegar a Adam's Rib, Angel encontrou uma irmã mais nova, Henriet. A menina tinha os mesmos traumas das outras personagens:

Ela era quieta e adorável, mas era uma garota que se cortava, cortava a própria pele, sempre que podia. Seus olhos eram inocentes e confiantes, mas sua pele era cheia de cicatrizes. Ela se cortava com tesouras e lâminas de barbear, como se não pudesse sentir dor 64 (HOGAN, 1997, p. 118).

Henriet não falava e feria a si própria, o que são possíveis consequências de eventos traumáticos.

A construção de barragens foi o motivo pelo qual Bush decidiu viajar a Two-Town no norte. Ela estava determinada a parar a devastação das terras. Angel foi junto para conhecer sua mãe, que diziam estar vivendo em uma cidade próxima de Two-Town chamada New Hardy, Dora-Rouge queria morrer ao lado do seu povo, os Fat-

\footnotetext{
61 "We $[\ldots]$ hurried along, half-running, both of us certain you would be hurt".

62 'Hannah sat in a rocking chair across the room, her back to the door. 'She's not my baby,' she said. 'My baby died at birth"”.

63 "'Keep it away from me. It's not mine".

64 "She was lovely and quiet, but she was a girl who cut herself, cut her own skin, every chance she had. Her eyes were innocent and trusting, but her skin was full of scars. She cut herself with scissors and razor blades, as if she could not feel pain".
}

Espaço Ameríndio, Porto Alegre, v. 8, n. 2, p. 65-86, jul./dez. 2014. 
Eaters; e Agnes precisava acompanhar sua mãe. Foi uma longa e cansativa jornada até chegarem ao seu destino; Agnes não resistiu e acabou morrendo no caminho.

Depois de alguns dias na terra dos Fat-Eaters, Angel finalmente viu sua mãe. Hannah havia sido avisada de que sua bisavó e sua filha estavam atrás dela, por isso decidiu aparecer em um domingo. Angel nadava no lago quando sua mãe chegou: "Dora-Rouge e eu logo vimos que Hannah ainda vivia em um mundo perigoso, ou talvez um mundo perigoso vivia dentro dela"65 (HOGAN, 1997, p. 230). Angel examinou o rosto de sua mãe à procura de semelhanças, mas Hannah não gostava de ser observada. No início, elas não conversavam nem chegavam perto uma da outra. "Eu havia imaginado esse encontro tantas vezes, mas nunca desse jeito. Qualquer ligação entre nós havia sido interrompida há muito tempo. Ela era, como dizia Bush, uma parede, um lugar sem alicerce"66 (HOGAN, 1997, p. 230), percebe Angel.

$\mathrm{Na}$ casa de Tulik, onde estão hospedadas, ocorre o primeiro contato verdadeiro entre as duas, quando Hannah diz: "'Eu nunca bati em você'" 67 , e, de novo, "[e]u nunca encostei a mão em você [...]. Acho que você devia saber disso'"68 (HOGAN, 1997, p. 231). Angel compreende que, na cabeça de Hannah, "eu era o acusador, a prova de sua culpa. Eu tinha as feridas de Hannah no rosto. Eram as evidências do que havia acontecido"69 (HOGAN, 1997, p. 231). Ela fica decepcionada porque sabe que nunca serão próximas. Nunca serão como mãe e filha: "Vejo que não havia amor dentro dela, nada que pudesse me amar, nada que jamais pudesse ter amado"70 (HOGAN, 1997, p. 231). Mais tarde, Angel descobre que Hannah havia usado armas contra ela: fio incandescente, dentes, até mesmo fogo. A mãe não suportava a ideia de ter uma filha. Bush tenta confortar a garota, dizendo que a culpa não era de Hannah. Os abusos que ela sofrera

\footnotetext{
65 "Dora-Rouge and I both could see in a glance that Hannah still resided in a dangerous world, or maybe it was that a dangerous world lived inside her".

66 "I had imagined this meeting so many times, but none of them was like this. Any path between us had long been closed. She was, as Bush said, a wall, a place to go with no foundation".

67 “'I never hit you"”.

68 "'I never laid a hand on you [...]. I think you ought to know that"”.

69 "I was the accuser, the sign of her guilt. I wore the wounds of Hannah on my face. They were evidence of what had happened".

70 "I see that there was no love inside her, nothing that could love me, nothing that could ever have loved".
}

Espaço Ameríndio, Porto Alegre, v. 8, n. 2, p. 65-86, jul./dez. 2014. 
eliminaram qualquer possibilidade de ter uma vida feliz e saudável.

Certa noite, depois de sonhar que sua mãe estava morta, Angel vai atrás dela em uma cidade próxima. Em uma casa sem pintura e em mau estado, Hannah está deitada inconsciente em uma cama com uma atadura manchada de sangue em volta da cintura. Duas vizinhas contam o que aconteceu: Hannah foi abandonada pelo caçador e teve de achar outro homem para alimentá-la. Seu nome era Eron, um homem vindo de uma família indígena decente que se tornou um problema após voltar do internato. Ele foi morar com Hannah, mas logo passou a temê-la:

Eron tinha a impressão que sempre havia outra pessoa no recinto. Às vezes, mais do que uma. A casa de Hannah era fria como o vento invernal, ele dizia. Certa noite, ele sentiu algo tocá-lo. 'Ela é um fantasma', ele contou ao irmão. 'Ela não é uma mulher de verdade, de jeito algum 71 (HOGAN, 1997, p. 246).

Assim como as outras pessoas, ele também percebeu que havia algo de muito errado com Hannah. Um dia, ele a esfaqueou e, em seguida, esfaqueou a si próprio. Antes de morrer, disse aos primos que ela havia implorado para ser morta: "Hannah sonhava com corpos congelados. 'Me mate', ela falou para ele. 'É a única maneira'"72 (HOGAN, 1997, p. 247).

As mulheres ainda fornecem informações que Angel desconhecia:

\begin{abstract}
Algumas pessoas sempre acharam que Hannah devia ter sido mandada para longe. Talvez até morta. As pessoas acreditavam que ela era um perigo para os demais. Um dos seus filhos comia vidro e mastigava lâminas de barbear. Sabíamos o que havia acontecido com você, seu rosto, como, feito um cachorro, ela mordeu seu rosto com os dentes. Foi pior para você, talvez porque você se parecia com ela. Ela odiava você por isso, por ter nascido do corpo dela, ter sido parte dela $^{73}$ (HOGAN, 1997, p. 247).
\end{abstract}

\footnotetext{
71 "'Eron said it always felt like someone else was in the room. Sometimes more than one. Hannah's house was cold as a winter wind, he said. One night he felt something touch him. 'She's a ghost,' he told his brother. 'She's not a real woman at all'”.

72 "Hannah dreamed of frozen bodies. 'Kill me then,' she told him. 'It's the only way"'.

73 “'There were people all along who thought Hannah should have been sent away. Maybe even killed. People believed she was a danger to others. One of her children ate glass and chewed razor blades. We knew what had happened to you, your face, how, like a dog, she bit your face with her teeth. It was worse for you, maybe because you looked like her. She hated you for that, for coming from her body, being part of her"”.
}

Espaço Ameríndio, Porto Alegre, v. 8, n. 2, p. 65-86, jul./dez. 2014. 
Essas palavras fazem Angel concluir que sua mãe "era um canibal, uma coisa gelada que odiava a vida"74 (HOGAN, 1997, p. 247). Ela era o wétiko, a presença maligna das histórias tradicionais indígenas que aterrorizava outros seres. Dora-Rouge disse que outra força cruel já havia possuído uma mulher e congelado seu coração. Aconteceu em 1936, "o ano da fome"75. Uma mulher que vivia em uma casa de neve comeu a carne dos familiares (canibalismo) e se tornou a amante do gelo (coração gelado). Certo dia, dois caçadores encontraram-na e se apiedaram dela, pois sabiam que não era sua culpa. Enquanto eles preparavam uma refeição para a mulher, ela os observava, com vontade de comer a carne do corpo deles. Assim como Hannah, ela afirmou: "Vocês têm que me matar. Não há outra saída"”76 (HOGAN, 1997, p. 248). Ela os atacou com uma faca; na briga, eles conseguiram matá-la. Foram presos uma semana depois, mas estavam satisfeitos, porque sabiam que havia equilíbrio no mundo novamente.

Quando vê o corpo de sua mãe, Angel compreende o quanto Hannah havia sofrido: "Ela estava coberta por cicatrizes"77 (HOGAN, 1997, p. 252). No fim das contas, Hannah deixou algo bom para Angel: uma irmãzinha. Angel a chama de Aurora e decide assumir a responsabilidade de cuidar dela. Elas fazem parte de uma nova geração: aqueles que foram capazes de superar os traumas, que nunca estarão sozinhos, que amam e são amados.

\section{Considerações finais}

Hannah, a mãe da protagonista da narrativa, Angel, passou por experiências traumáticas durante sua infância: ela foi surrada, queimada, forçada a ter relações sexuais com homens repugnantes. A herança de sua mãe Loretta foram as cicatrizes espalhadas pela sua pele. $\mathrm{Na}$ iminência da insanidade, ou mesmo da morte, ela se entregou às forças malignas que tentavam entrar no seu corpo. Ela se tornou fria

\footnotetext{
74 "[Your mother] was a cannibal, a cold thing that hated life"

75 “[T] he starvation year".

76 "'You have to kill me. There's no other way"”.

77 "She was covered with scars".
}

Espaço Ameríndio, Porto Alegre, v. 8, n. 2, p. 65-86, jul./dez. 2014. 
como o gelo, para que ninguém mais pudesse machucá-la. O preço terrível dessa atitude foi que ela também se tornou vazia. Era incapaz de sentir qualquer coisa ou de demonstrar qualquer tipo de afeto pelo próximo.

Em Solar Storms, Hannah é a pessoa mais traumatizada, sempre desperta e à espera de ser ferida. Utilizando histórias, linguagem e perspectiva indígenas, a autora Linda Hogan consegue criar uma personagem que encarna a presença sombria do trauma.

\section{Referências bibliográficas}

ALLEN, Paula Gunn. Studies in American Indian Literature. New York: Modern Language Association of America, 1983.

FORBES, Jack D. Columbus and Other Cannibals. New York: Seven Stories Press, 2008.

HERMAN, Judith. Trauma and Recovery. New York: Basic Books, 1997.

HOGAN, Linda. Solar Storms. New York: Simon \& Schuster, 1997.

SILKO, Leslie M. Language and Literature from a Pueblo Indian Perspective. In: English Literature: Opening Up the Canon. Baltimore: Johns Hopkins University Press, 1981.

VERNON, Irene S. "We Were Those Who Walked out of Bullets and Hunger": Representation of Trauma and Healing in "Solar Storms". The American Indian Quarterly, Washington, v. 36, n. 1, p. 34-49, 2012.

Espaço Ameríndio, Porto Alegre, v. 8, n. 2, p. 65-86, jul./dez. 2014. 